\author{
Marquette University \\ e-Publications@Marquette
}

College of Education Faculty Research and

Publications

Education, College of

$11-29-2018$

\title{
Applying Task Force Recommendations on Integrating Science and Practice in Health Service Psychology Education
}

Timothy P. Melchert

Marquette University, timothy.melchert@marquette.edu

Sharon Berry

Catherine Grus

Prerna Arora

Andres De Los Reyes

See next page for additional authors

Follow this and additional works at: https://epublications.marquette.edu/edu_fac

Part of the Education Commons

\section{Recommended Citation}

Melchert, Timothy P.; Berry, Sharon; Grus, Catherine; Arora, Prerna; De Los Reyes, Andres; Hughes, Tammy L.; Moyer, Bruce Eugene; Moye, Jennifer; Oswald, Frederick L.; and Rozensky, Ronald H., "Applying Task Force Recommendations on Integrating Science and Practice in Health Service Psychology Education" (2018). College of Education Faculty Research and Publications. 519.

https://epublications.marquette.edu/edu_fac/519 


\section{Authors}

Timothy P. Melchert, Sharon Berry, Catherine Grus, Prerna Arora, Andres De Los Reyes, Tammy L. Hughes, Bruce Eugene Moyer, Jennifer Moye, Frederick L. Oswald, and Ronald H. Rozensky 
Marquette University

\section{e-Publications@Marquette}

\section{Education Faculty Research and Publications/College of Education}

This paper is NOT THE PUBLISHED VERSION; but the author's final, peer-reviewed manuscript. The published version may be accessed by following the link in the citation below.

Training and Education in Professional Psychology, (2018). DOI. This article is (C American Psychological Association and permission has been granted for this version to appear in ePublications@Marquette. American Psychological Association does not grant permission for this article to be further copied/distributed or hosted elsewhere without the express permission from American Psychological Association.

\section{Applying Task Force Recommendations on Integrating Science and Practice in Health Service Psychology Education}

Timothy P. Melchert ${ }^{\mathrm{a}}$, Sharon Berry ${ }^{\mathrm{b}}$, Catherine Grus ${ }^{\mathrm{c}}$, Prerna Arora ${ }^{\mathrm{d}}$, Andres De Los Reyes ${ }^{\mathrm{e}}$, Tammy L. Hughes ${ }^{f}$, Jennifer Moye ${ }^{g}$, Frederick L. Oswald ${ }^{\text {h }}$, and Ronald H. Rozensky ${ }^{i}$

${ }^{a}$ Marquette University

${ }^{b}$ Children's Minnesota

${ }^{\mathrm{c}}$ American Psychological Association Education Directorate

${ }^{d}$ Columbia University

e University of Maryland at College Park

${ }^{f}$ Duquesne University

gVA Boston Healthcare System and Harvard Medical School

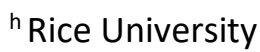

'University of Florida

Corresponding Author: Timothy Melchert, Department of Counselor Education and Counseling Psychology, 113K Schroeder Complex, Marquette University, Milwaukee, WI 53201

(414-288-7379, tim.melchert@marquette.edu) 


\section{Abstract}

The proper role of research skills and training to conduct research in professional psychology education has been controversial throughout the history of the field. An extensive effort was undertaken recently to address that issue and identify ways the field might move forward in a more unified manner. In 2015, the American Psychological Association (APA) Board of Educational Affairs convened a task force to address one of the recommendations made by the Health Service Psychology Education Collaborative in 2013. That recommendation stated that the education and training of HSPs include an integrative approach to science and practice that incorporates scientific-mindedness, training in research skills, and goes well beyond merely "consuming" research findings. The task force subsequently developed recommendations related to the centrality of science competencies for HSPs and how these competencies extend beyond training in evidence-based practice. This manuscript discusses the findings of the task force and the implications of its recommendations for education and training in HSP. The challenges and opportunities associated with implementing these recommendations in HSP graduate programs are examined.

Key Words: health service psychology, integrating science and practice, psychology education and training, science competencies, evidence-based practice

The question of how best to integrate training for science and practice in health service psychology (HSP) education has been a source of contention and debate across the history of the profession. In fact, this question was present from the very beginning of the field, including at the seminal Boulder Conference in 1949 when the scientist-practitioner model of professional psychology education was established. The most influential resolution of the Boulder Conference was the decision "to recommend the training of the clinical psychologist for research and practice, with equal emphasis on both" (Raimy, 1950, p. 79). The conference report explained that "A few participants were strongly in favor of concentrating exclusively on training for service...Some other participants were as strongly opposed to diluting a good research training with time spent on applied diagnostics and therapy...In the face of such an apparent split, reconciliation was surprisingly rapid and almost unanimous" (Raimy, 1950, p. 79).

Despite the nearly unanimous decision of the Boulder conferees to adopt the scientist-practitioner model of training in professional psychology, the decision to train students as both scientists and practitioners soon received significant criticism (Clark, 1957; Hughes, 1952). The 1965 Chicago Conference on the Professional Preparation of Clinical Psychologists approved a recommendation that professional psychology experiment with different models of training (Hoch, Ross, \& Winder, 1966), and the practitionerscholar Psy.D. model was subsequently approved at the Vail Conference in 1973 (Korman, 1976). The National Council of Schools of Professional Psychology formed the following year and emphasized clinical competencies while deemphasizing research skills (Peterson, McHolland, Bent, Davis-Russell, Edwall, Polite, et al., 1992). But disillusionment with the growing practice emphasis of the APA led thousands of primarily experimental psychologists to break away from the APA to form the American Psychological Society in 1988 (currently named the Association for Psychological Science). Further concern about the erosion of research training in clinical psychology led to the founding of the Academy of Psychological Clinical Science in 1995 and the Psychological Clinical Science Accreditation System in 2007 (McFall, Treat, \& Simons, 2015). Over these decades, literally hundreds of theoretical orientations for understanding personality, psychopathology, and psychotherapy were also promulgated (e.g., Corsini \& Wedding, 2008, identified over 400), and several of 
these became highly controversial and discredited as well (e.g., Norcross, Koocher, \& Garofalo, 2006). By the early 2000s, the conflicts and divisions within psychology had grown so serious that some leading psychologists openly questioned whether the field would be able to continue as a single discipline (Benjamin, 2001, Sternberg, 2005).

Conflicts and divisiveness within the field began subsiding, however, as developments unfolded in the early 2000s. The movement toward evidence-based practice in health care generally (Institute of Medicine, 2001) as well as in psychology specifically (APA Presidential Task Force on Evidence-Based Practice, 2006) was particularly helpful in this regard. This movement had broad support across the health care professions and within professional psychology, but it did little to resolve the historical disagreements and sources of confusion regarding the proper role of research skills and conducting research in HSP education.

\section{Formation of the Health Service Psychology Education Collaborative}

In 2010, the APA Board of Educational Affairs approved the creation of the Health Service Psychology Education Collaborative (HSPEC) to address key concerns related to education and training for the professional practice of psychology. HSPEC was a multi-year, multi-organizational effort specifically concerned with the disorganized and fragmented approach to professional psychology education in the U.S. As HSPEC noted, "The current state of education and training reveals a fragmented system of educational models, competencies, entry qualifications, licensure criteria, and nomenclature that is confusing to potential students and the public" (HSPEC, 2013, p. 412). The vision of HSPEC was to move beyond this state of affairs to a more unified and coherent approach to education and training in the field. To achieve this vision, HSPEC focused on the role of competencies in HSP education, admission requirements for doctoral education in the field, the development of more uniform accreditation requirements across the U.S., the need for more workforce analysis research for HSPs, as well as the integration of science and practice in HSP education.

Given the significance and breadth of the issues that HSPEC was addressing, no one group was assigned responsibility. Instead, HSPEC included representatives of APA, the Council of Chairs of Training Councils, and the Council of Graduate Departments of Psychology. At its initial meeting in 2010, members of the Collaborative began reviewing data from a survey of 1,330 educators, supervisors, students, and members of APA governance groups along with a variety of other data and reports. The Collaborative reached consensus on several core issues which led to the identification of seven key topics related to the provision of quality education and training in HSP. Recommendations to address these seven topics were then developed with corresponding rationales and proposed action steps. Taken together, they formed the report titled "Professional psychology in health care services: A blueprint for education and training" (hereafter referred to as the Blueprint; HSPEC, 2013). The seven main recommendations included in the Blueprint are reproduced in Appendix I.

The fifth HSPEC (2013) Blueprint recommendation focused on the role of science in HSP education. Given the long-standing disagreements in the profession about the importance of developing competencies in research and science, this recommendation has special significance for education and training in HSP. The recommendation states that "The integration of science and practice requires HSPs to implement evidencebased procedures, utilize a sophisticated degree of scientific mindedness, and do more than 'consume' research findings" (HSPEC, 2013, p. 417). The rationale provided for this recommendation began by noting that "Psychology is a STEM discipline. As a result, the practice of psychology is scientifically based, and science 
is not merely one aspect of a continuum from science to practice. A crucial component of health service psychology, science must be part of all education and training" (p. 417). The report further concluded that "Psychologists who are health service providers need to learn the skills necessary to conduct research and evaluate the applicability of research to clinical practice" (p. 417). These HSPEC recommendations are also consistent with the recent revision of the Standards of Accreditation for Health Service Psychology by the APA Commission on Accreditation (APA, 2015) that went into effect in 2017. The HSPEC findings and revision of the accreditation standards are both important indications of the field's reaffirmation of its commitment to science-practice integration and the importance of science and research competencies in HSP education. HSPEC (2013) also identified the competencies that should be incorporated into the learning outcomes expected of students in all HSP programs (see Appendix II).

The HSPEC (2013) Blueprint also referred to the historical disagreement regarding the importance of learning research skills by noting that "The development of 'models of clinical training' has unintentionally dichotomized the field into those programs that train for research careers and those programs that train for practice, with the majority of programs falling somewhere in between" (p. 417). The Blueprint then suggested that it was time for HSP to leave this disagreement behind by taking a more unified approach to research training:

However, HSPEC believes that all HSPs, regardless of career path, need to be able to conduct research that applies existing knowledge to solve practical problems.... Activities such as conducting program evaluations, evaluating the efficacy of interventions, and quality improvement interventions in one's practice require HSPs to be more than mere consumers of research. Rather, the integration of science and practice must produce HSPs capable of both asking and answering questions in an evidencebased, scientific manner. (pp. 417-418)

\section{Task Force Recommendations for Competencies in Science}

In 2015, the APA Board of Educational Affairs created a task force to take action toward implementing the fifth HSPEC (2013) recommendation. A call for nominations was widely disseminated and the Board of Education Affairs appointed seven members, a liaison from the Board (Tammy Hughes), a chair (Sharon Berry), and support from the APA Education Directorate through Catherine Grus. Task Force members were selected to reflect diversity as well as a broad range of expertise in psychology education and training. The Task Force submitted their final report to the Board of Educational Affairs in 2016; (the full report can be found at http://www.apa.org/ed/resources/index.aspx under the heading for "Other Resources and Recommendations for Education").

Based on the conclusions of the HSPEC (2013) Blueprint, the findings of the Task Force were predicated on the assumption that the HSP science competencies are key goals for all graduate education and training programs, for all faculty and staff in those programs, and for all students and trainees throughout their education, training, and across their entire professional careers. Behavioral science knowledge and health care practices are evolving rapidly and psychologists must therefore espouse an attitude of lifelong learning and continually update their knowledge and skills. Data on the decreasing halflife of scientific data and its applicability to practice also support this assumption (Neimeyer, Taylor, \& Rozensky, 2012). 
The Task Force designed its recommendations to apply across the many recognized specialties in professional psychology and the wide range of scientific and practice areas encompassed within the field. The Task Force noted that the literature related to evidence-based practice (APA Presidential Task Force on Evidence-Based Practice, 2006) is critical but not the only focus of HSP education and training. The expectations related to scientific competence, including the carrying out of research as an expected component of graduate education, further assumes that trainees develop competence in all the HSP recommended competencies and domains.

Based on these assumptions, the Task Force concluded that in order to achieve the integration of practice and science for all HSPs, all HSP education and training programs strive to develop the HSPEC science competencies (listed in Appendix II) for all their students and trainees. More specifically, the Task Force further concluded that, as a result of their education and training, all HSPs:

- Are prepared (via their education and training) to conduct research using scientific tools, techniques, and methods to solve both basic and applied problems.

- Produce, evaluate, and disseminate scientific knowledge for purposes of generalizable or local knowledge and its application.

- Utilize a sophisticated degree of scientific mindedness (Bieschke, Fouad, Collins, \& Halonen, 2004) and do more than consume research. Consistent with the Blueprint, the integration of research and practice in education and training activities is critical for producing HSPs who competently and habitually apply scientific thinking in both their research endeavors and clinical practice.

- Are capable of both asking and answering questions in a scientific manner.

- Are trained as competent researchers who understand clinical issues.

- As part of their doctoral education and training, will have conducted an empirical research project that includes the collection, analysis, and interpretation of data. The project will examine a research question that is relevant to psychological science and/or clinical practice (e.g., treatment efficacy, program evaluation, quality improvement studies).

- Are trained as competent clinicians who understand the underlying science in their area(s) of practice.

- Are trained to engage in scientifically based practice and develop the ability to review the scientific, evidencebased literature to make informed decisions for carrying out diagnostic and treatment interventions across practice settings and diagnostic groups.

To assist HSP education and training programs in developing, expanding, adopting, and evaluating research competencies for HSPs, the Task Force also identified student-focused behavioral anchors for each of the nine science competencies included in the HSPEC (2013) Blueprint. In addition, the Task Force identified a range of program activities and methods that can be used to evaluate those competencies along with resources that can be used to promote the development of each competency. The behavioral anchors and associated program activities were specified at three levels of education and training: readiness for practicum, readiness for internship, and readiness for entry into practice.

To illustrate the nature of these recommendations across the three levels of training, the Table below reproduces the recommendations that address the first of the nine research and science competencies identified in the HSPEC (2013) Blueprint. The columns in the Table titled "Behavioral Anchors for Trainees" reflect a synthesis of items generated by the Task Force along with those from existing competency models, including the competency benchmarks developed by APA (APA, 2011), counseling psychology (Council of Counseling Psychology Training Programs, 2013), health psychology (Society for Health Psychology, 2016), and clinical psychology (University of Saskatchewan Department of Psychology, 2013). Similarly, in the 
columns titled "Program Activities," suggested methods for teaching and evaluating each competency were referenced when appropriate or were generated by the Task Force. In some cases, competencies overlapped such that the same method or activity can be used to teach and evaluate several competencies. In addition, the final column lists educational resources that can be used to help achieve the various competencies. These resources were certainly not meant to be exhaustive and many other useful examples could have been included. The Task Force also encouraged programs to specify the means by which they will evaluate the success of each trainee in developing the behavioral anchors for each competency at each level of training. The behavioral anchors, program activities, and educational resources for all nine of the HSPEC (2013) science competencies can be found in the complete Task Force report (at http://www.apa.org/ed/resources/index.aspx).

Of critical importance to the Task Force was the understanding that these recommendations were offered as guidance to the field, not prescriptions. Consistent with the APA Commission on Accreditation Standards for Accreditation (2015), each academic department or training program was viewed as having the flexibility and academic freedom to adopt and adapt these recommendations to reflect local programming philosophy, knowledge and skills specific to the specialization, as well as profession-wide competencies required of accredited programs in health service psychology (APA CoA, 2015). The descriptors, definitions, and recommendations in the Task Force report were not offered as "bright lines" or enforceable standards, but rather as guidance to help education and training programs adopt the expectations of the Blueprint.

\section{Implications for HSP Education and Training}

The Task Force's emphasis on integrating science and practice in HSP education serves to establish HSPs as making distinctive and valued contributions to health care. Such integration across all education and training programs in HSP also reflects a commitment to reinforcing the core value that psychology places on current, consensus-based professional standards for quality in education and training. First-hand engagement in the scientific research process along with the provision of clinical services will strengthen students' knowledge and skill in scientific thinking and evidence-based practice, and thereby strengthen both practice and research competencies among trainees in HSP programs.

Accredited HSP programs vary in their emphasis on research-based competencies but, consistent with current APA accreditation standards, all are addressing scientific competencies as a general expectation for all their graduates (APA, 2017). Since the HSPEC (2013) Blueprint was developed, the APA Standards of Accreditation for Health Service Psychology (APA, 2015) have incorporated the expectation for the integration of science and practice in all programs. Given natural and expected variations in curriculum, programs themselves are tasked with the responsibility of how best to determine the implementation and measurement of student learning that reflects the integration of science and practice into the curriculum. To reach this goal, it is suggested that programs take a developmental approach where the specific learner's levels of knowledge and skills are monitored across the curriculum so that graduate student learning is sequential, cumulative, and scaffolded toward more independence, even (and especially) as contextual variables become more complex. It is also suggested that programs explicate how the priorities of the local curriculum and learning activities are consistent with the program's goals and national definitions of HSP, such as those provided by the APA Commission on Accreditation (APA, 2015, 2017) and HSPEC (2013). The Task Force suggestions for behavioral anchors and learning activities were intended to be practical, realizable, and measurable, and not require extensive resources for programs newly embarking on the local, programmatic implementation of this national expectation. 
As a first step in implementing these recommendations, programs should review their current infrastructure and graduation requirements to ensure that scientific knowledge and research methods are built in as essential aspects of the curriculum. Again, graduate-level HSP competency is no longer achieved simply by consuming scholarly works and research; rather the expectation now is that all students will be able to engage in and produce research products (APA, 2017). Many programs may already require students to lead or be heavily involved in projects involving randomized controlled clinical outcomes studies, multiple baseline single subject research, or the seeking of government or foundation grant funding for empirical research. Other programs expect students to do program evaluation studies where important local clinical or community questions are investigated using a range of skills in experimental design and data analysis. Departments without a requirement for empirically based research projects (e.g., a thesis or dissertation) would need to identify how best to meet the new expectations that each student be able to participate in and produce research versus merely consume it. This would provide an opportunity to take advantage of the myriad resources identified by the Task Force to facilitate competency development, some of which might be incorporated into existing program requirements.

Programs could also benefit from conducting a needs assessment to identify strengths and weaknesses within their curriculum, including possible or desired outcome measures (e.g., research productivity of students, graduation rates, time to degree, EPPP pass rates). They should also assess student level of readiness for the next level of education, training, and/or clinical practice using the grid developed by the Task Force for each of the science and research competencies. Once faculty in a program identify growth opportunities, they may find it useful to plan a graduated model for implementation where action steps are prioritized and sequenced to facilitate practical curriculum improvements and avoid overwhelming the program environment. Further, the expertise of current faculty should be considered including existing capacities that already exist and new capacities that require additional curricular expansion and/or additional resources or partnerships. A thorough review of outcome measures would also aid in this process. Useful questions to ask at this point include whether faculty are satisfied with the type of activities they require (e.g., quantitative and qualitative projects, quality improvement or program evaluation models)? Is there consensus that the outcome measures used are reliable and valid for decision making regarding the attainment of the expected competencies? Although student competency development often follows from a well-planned sequence of education and training experiences, faculty should also consider what types of variations are allowable for a student to demonstrate their competency. It is better for a program to plan for rather than to react to those variations as much as possible.

The Task Force believes that most programs in recent years, including Psy.D. programs, already include empirical learning opportunities for all their students that are consistent with their local and national pedagogical model and APA (2015) accreditation standards. The Task Force believes that the goal of training critical, scientific thinking should be implemented on the local level, yet still meet the overarching expectations of the national view of HSP being a scientifically based discipline.

Each program, regardless of the training model it uses, has individual strengths, resources, and opportunities to build scientific competencies, just as each program has unique strengths, resources, and opportunities to build clinical competencies in their students. Thus, programs should take advantage of their unique, local opportunities to build scientific competencies as well as clinical competencies and work toward integrating the two. We also appreciate how new expectations and fresh ideas can stimulate new ideas for strengthening a program, including new teaching methods and practices that are helpful to both faculty and students. Therefore, the integration of science and practice can, and should, embrace innovation across both 
these domains, as well as be balanced with established science- and practice-based learning activities. The Task Force table with behavioral anchors, learning activities, and resources for developing science competencies should be helpful to faculty who are considering how to modify their HSP programs to strengthen science-practice integration.

Health service psychology will benefit in important ways if these recommendations are widely adopted. Doing so would enhance public understanding that psychology, as a profession and a discipline, is grounded firmly in science. To the extent that developing HSP science competencies becomes a consistent expectation, it could not only enhance and strengthen education and training curricula in HSP but may also help unify the education and training community within the field. It would also set clear expectations to undergraduate students and educators that graduate training in psychology is science focused, potentially leading to a more uniform science- and practice-driven undergraduate curriculum for students who plan to study HSP at the graduate level. More agreement on undergraduate and graduate training to develop HSP science competencies might also lead to innovations in education and training that could be broadly implemented across courses over time. Further, the driving spirit of these changes might diminish the historical focus on differences in education and training associated with alignment to a specific training model. Adopting these recommendations will also reinforce current directions in HSP education and training. These include the now common use of the phrasing "health service psychology" instead of "professional psychology" and identification of HSP as a science-based health services profession. The newly adopted APA Standards of Accreditation already state that science is the foundation of HSP, and doctoral students and interns must be able to demonstrate the integration of science and practice (APA, 2017).

Broad implementation of the above recommendations, however, would represent a major culture shift for those who hold philosophies for education and training in HSP that have historically embraced a program's right to set their curriculum vs. having a standardized or core curriculum imposed on them (Benjamin, 2001). Such a culture shift might be viewed by some as a negative outcome of implementing these recommendations, and some psychologists likely view diversity in the implementation of HSP education and training as both a foundational principle and a strength of the field. Though there is room for flexibility, innovation, and program-specific diversity in the implementation of the task force recommendations and APA accreditation standards, some psychologists likely view these expectations as curtailing academic freedom.

Faculty within some HSP graduate programs will also face challenges to the implementation of the Task Force recommendations. Limited resources, particularly staffing and time that are already limited, may serve as an impediment to implementing these recommendations within some psychology graduate training programs. Concerns about adding requirements to what is seen as an already full training sequence may be heightened by the increasing clinical demands that are believed to be needed by students in order to be competitive for clinical internships (Belar, 2006). Moreover, as expectations for faculty engagement in administrative tasks in higher education increases (Mamiseishvili \& Rosser, 2011), faculty may have limited time for appropriately modifying existing courses and core requirements within the training sequence to address these recommendations. Further, faculty may face time constraints related to the increased mentoring needed to strengthen student skills and competencies in the integration of science and practice (Hyatt \& Williams, 2011).

A second and related challenge to implementing these recommendations stems from individual differences in attitudes or beliefs among trainees and faculty regarding the importance of integrating practice 
and science in HSP. Research suggests that, in fact, it would be prudent to expect these challenges. Specifically, in both assessment and intervention services, a noticeable gap exists between the knowledge gleaned from research and the actual practices seen in service delivery (e.g., Jensen-Doss \& Hawley, 2010, 2011; Kazdin, 2017). Multiple facets of attitudes and beliefs likely underlie the development and maintenance of the "research-practice gap" long observed in service delivery settings, including the belief that treatment outcome research is not generalizable because it relies on samples of clients who bear little resemblance to those seen in routine service settings (e.g., Weisz, Jensen-Doss, \& Hawley, 2006). These beliefs may have their origins in the training setting, the very context in which the recommendations discussed in this paper are to be implemented. Thus, a useful next step in the process of implementing the Task Force recommendations may be survey research focused on the attitudes and beliefs that HSP trainees and faculty hold regarding both integrating science and practice in general and the Task Force recommendations in particular. Simply administering these surveys, in and of themselves, may facilitate the implementation of these recommendations.

\section{Conclusions}

The above recommendations highlight the professional value that psychologists hold for our sciencebased profession and re-calibrate the bar that all programs need to meet to realize the values to which we aspire. Each training component along the continuum from doctoral program to internship and postdoctoral fellowship will play a role. Each of the competencies is slightly different at each stage, and the full Task Force report provides multiple ideas and resources from which to choose. Making changes using resources from a document such as this helps individual programs identify what works best within their faculty structures and current curricula.

One of the most important conclusions arrived at by the Task Force was that expectations related to competence in the science domain, including carrying out research as an expected component of graduate education, presupposes competence in all HSP competencies and domains. Critical to the Task Force was also the understanding that the recommendations made were offered as guidance to the field, and each academic department or training program continues to enjoy the flexibility and academic freedom to adopt and adapt these recommendations to reflect local programming philosophy, resources, and opportunities; knowledge and skills specific to particular specializations; as well as profession-wide competencies required of accredited programs in HSP. The overarching goal of all the recommendations was to ensure that HSPs utilize a sophisticated degree of scientific mindedness and learn to do more than "consume research findings."

Implementing these recommendations provides the field with an important opportunity to resolve confusion and divisiveness that have long plagued HSP across its history. Nonetheless, some training programs will likely face significant challenges in implementing these suggestions. It is hoped that the above discussion will assist all programs to achieve the vision of HSPEC (2013) to develop a more unified and coherent approach to education and training in HSP that is needed to help propel the field forward as it moves into the next stages of its development as a health services profession. 


\section{References}

American Psychological Association Presidential Task Force on Evidence-Based Practice. (2006). Evidencebased practice in psychology. American Psychologist, 61, 271-285.

American Psychological Association. (2011). Revised competency benchmarks. Retrieved from http://www.apa.org/ed/graduate/competency.aspx.

American Psychological Association, Commission on Accreditation. (2015). Standards of Accreditation for Health Service Psychology. Retrieved from http://www.apa.org/ed/accreditation/about/policies/standards-of-accreditation.pdf

American Psychological Association, Commission on Accreditation. (2017). Implementing regulation C-8 D profession wide competencies. Retrieved from http://www.apa.org/ed/accreditation/section-csoa.pdf.

APA Presidential Task Force on Evidence-Based Practice. (2006). Evidence-based practice in psychology. American Psychologist, 61, 271-285.

Belar, C. D. (2006). Graduate education in clinical psychology: "We're not in Kansas anymore". Training and Education in Professional Psychology, S(2), 69-79.

Benjamin, L. T., Jr. (2001). American psychology's struggles with its curriculum: Should a thousand flowers bloom? American Psychologist, 56, 735-742.

Bieschke, K. J., Fouad, N. A., Collins, F. L., \& Halonen, J. S. (2004). The scientifically-minded psychologist: Science as a core competency. Journal of Clinical Psychology, 60, 713-723.

Clark, K. E. (1957). America's psychologists. Washington, DC: American Psychological Association

Corsini, R. J., \& Wedding, D. (2008). Current psychotherapies (8 ${ }^{\text {th }}$ ed.). Belmont, CA: Thomson Brooks/Cole. Council of Counseling Psychology Training Programs (2013).

Council of Counseling Psychology Training Programs. (2013). Counseling psychology core competencies. Retrieved from: http://www.ccptp.org/assets/docs/copsy\%20competencies\%20final2.pdf

Health Service Psychology Education Collaborative. (2013). Professional psychology in health care services: A blueprint for education and training. American Psychologist, 68, 411-426.

Hoch, E. I., Ross., A. G., \& Winder, C. L. (1966). Professional preparation of clinical psychologists. Washington, DC: American Psychological Association.

Hughes, E. C. (1952). Psychology: Science and/or profession. American Psychologist, 7, 441-43.

Hyatt, L., \& Williams, P. E. (2011). 21st Century competencies for doctoral leadership faculty. Innovative Higher Education, 36(1), 53-66.

Institute of Medicine. (2001). Crossing the quality chasm: A new health system for the $21^{\text {st }}$ century. Washington, DC: National Academies Press

Jensen-Doss, A., \& Hawley, K.M. (2010). Understanding barriers to evidence-based assessment: Clinician attitudes toward standardized assessment tools. Journal of Clinical Child \& Adolescent Psychology, 39, 885-896.

Jensen-Doss, A., \& Hawley, K.M. (2011). Understanding clinicians' diagnostic practices: Attitudes toward the utility of diagnosis and standardized diagnostic tools. Administration and Policy in Mental Health and Mental Health Services Research, 38, 476-485.

Kazdin, A.E. (2017). Addressing the treatment gap: A key challenge for extending evidence-based psychosocial interventions. Behaviour Research and Therapy, 88, 7-18.

Korman, M. (Ed.). (1976). Levels and patterns of professional training in psychology. Washington, DC: American Psychological Association. 
Mamiseishvili, K., \& Rosser, V. J. (2011). Examining the relationship between faculty productivity and job satisfaction. Journal of the Professoriate, 5(2), 100-132.

McFall, R. M., Treat, T. A., \& Simons, R. F. (2015). Clinical science model. In R. L. Cautin \& S. O. Lilienfeld (Eds.), The encyclopedia of clinical psychology (pp. 1-9). New York: Wiley.

Neimeyer, G. J., Taylor, J. M., \& Rozensky, R. H. (2012). The diminishing durability of knowledge in professional psychology: A Delphi Poll of specialties and proficiencies. Professional Psychology: Research and Practice, 43(4), 364-371.

Norcross, J. D., Koocher, G. P., \& Garofalo, A. (2006). Discredited psychological treatments and tests: A Delphi poll. Professional Psychology: Research and Practice, 37, 515-522.

Peterson, R. L., McHolland, J. D., Bent, R. J., Davis-Russell, E., Edwall, G. E., Polite, K., Singer, D. L., \& Stricker, G. (1992). The core curriculum in professional psychology. Washington, DC: American Psychological Association.

Raimy, V. C. (1950). Training in clinical psychology. New York: Prentice Hall.

Society for Health Psychology (2016). Competencies in research for health psychologists. Retrived from https://societyforhealthpsychology.org/training/training-competencies/competencies-researchhealth-psychologists/

Sternberg, R. J. (2005). Unifying the field of psychology. In R. J. Sternberg (Ed.), Unity in psychology: Possibility or pipedream? (pp. 3-14). Washington, DC: American Psychological Association.

University of Saskatchewan Department of Psychology (2013). Core competencies of a clinical psychologist. Retrieved from: http://artsandscience.usask.ca/psychology/programs/ clinical/sub_pages/core_competencies.php

Weisz, J.R., Jensen-Doss, A., \& Hawley, K.M. (2006). Evidence-based youth psychotherapies versus usual clinical care: a meta-analysis of direct comparisons. American Psychologist, 61, 671-689. 
Table. Examples of APA BEA Task Force Recommendations for the Integration of Science and Practice in HSP Training, Activities and Resources for the First of Nine Competencies (full table is available at http://www.apa.org/ed/resources/index.aspx)

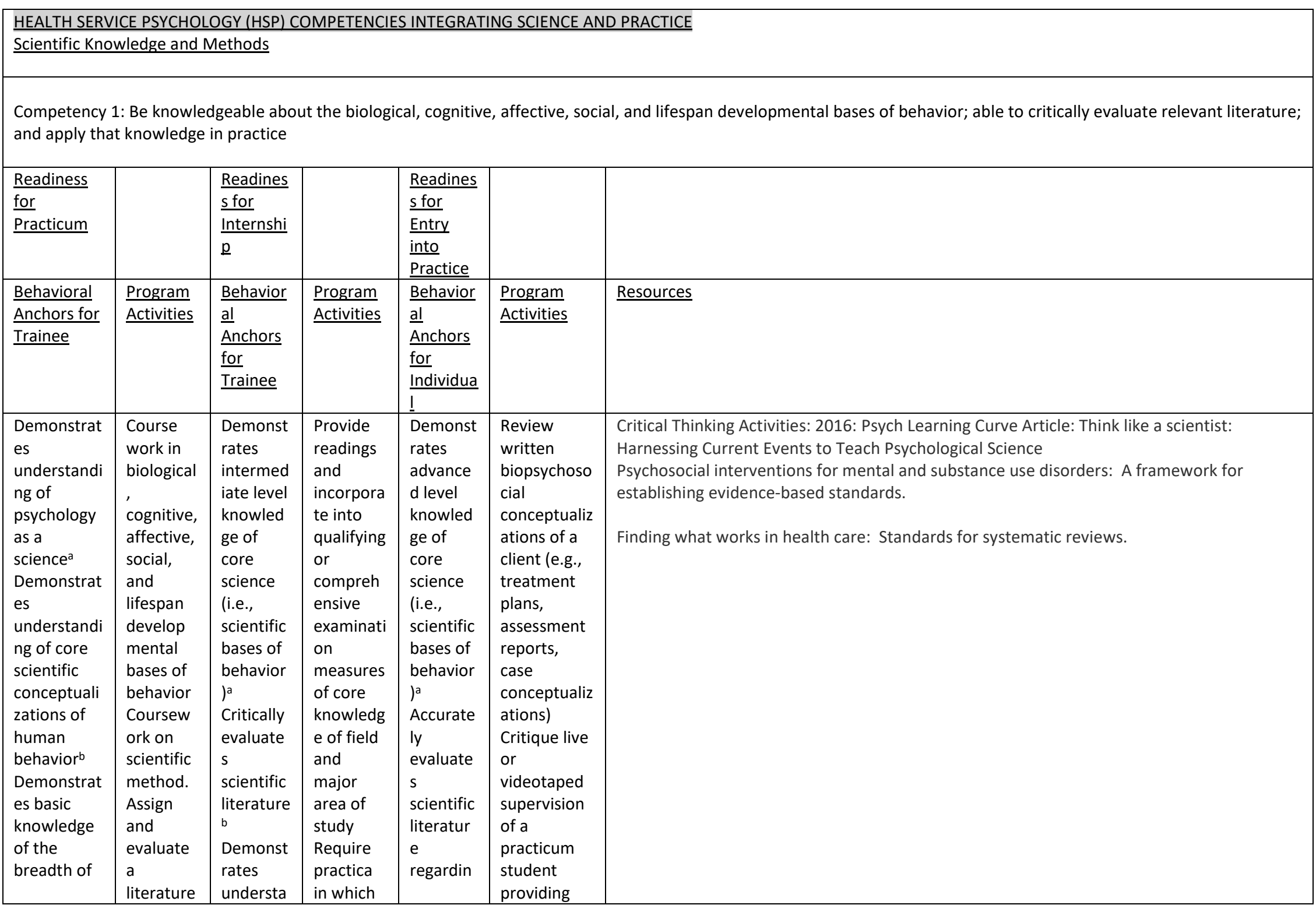




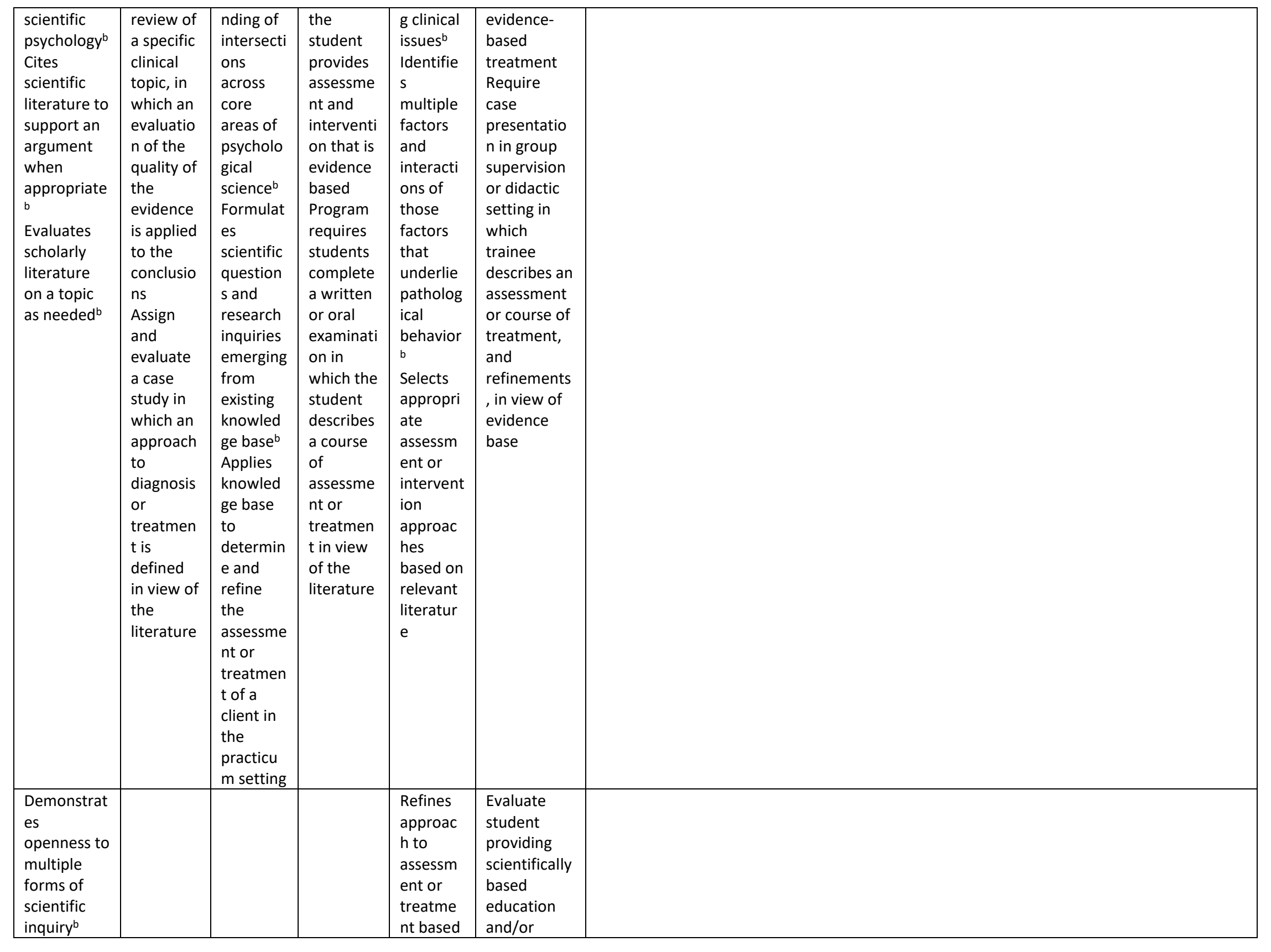




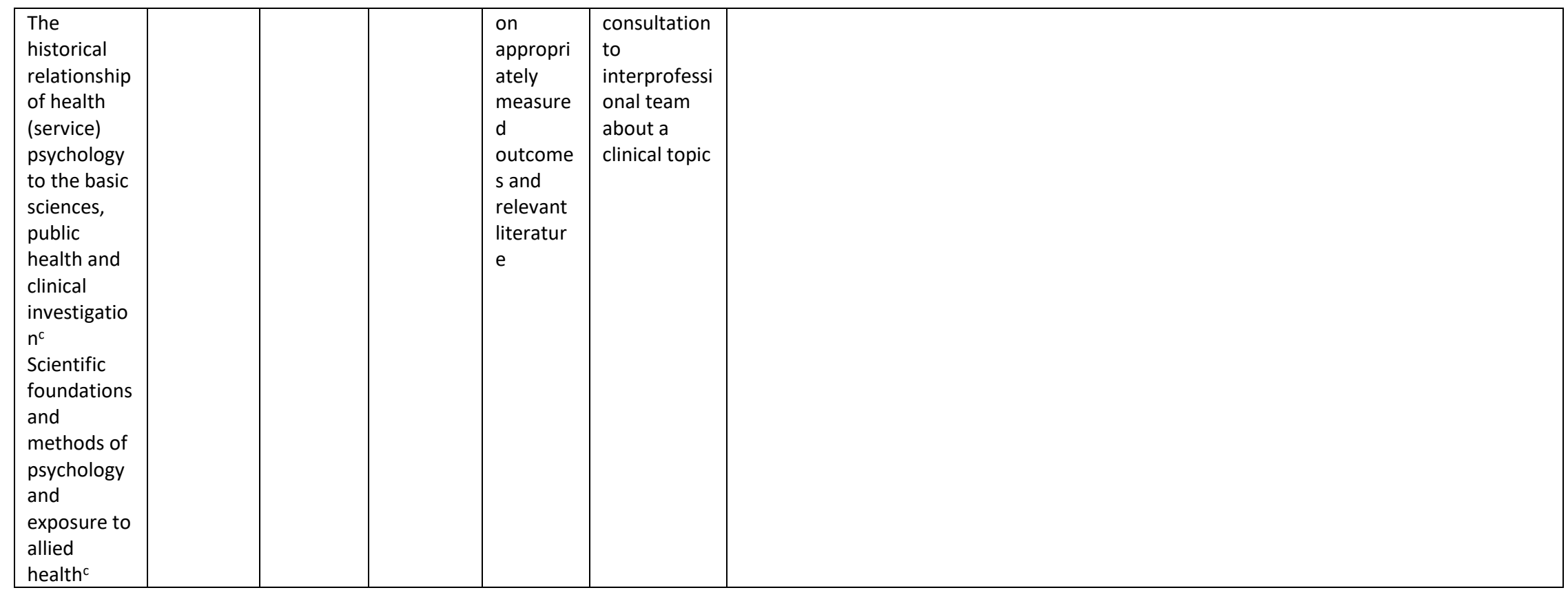

Note: ${ }^{a}$ APA, 2011; ${ }^{b}$ Council of Counseling Psychology Training Programs, 2013; ${ }^{c}$ Society for Health Psychology, 2016 ; ${ }^{d}$ University of Saskatchewan Department of Psychology, 2013. 


\section{Appendix I}

Recommendations of the Health Service Psychology Education Collaborative (2013)

Recommendation 1 . The competencies of psychologists who provide health services should be clearly articulated and understood by faculty, students, regulators, and the public.

Recommendation 2. There should be guidelines for minimal qualifications to enter doctoral programs that prepare health service psychologists.

Recommendation 3. Psychology needs to articulate and evaluate the competencies for each level of education and training of health service psychologists, as well as examine the sequence itself.

Recommendation 4. There needs to be increased focus on competency assessment in psychology education and training for the delivery of health care services.

Recommendation 5. The integration of science and practice requires health service psychologists to implement evidence-based procedures, utilize a sophisticated degree of scientific mindedness, and do more than "consume" research findings.

Recommendation 6. Psychology needs to engage in self-regulation for the education and training of health service psychologists by adopting a national standard of accreditation.

Recommendation 7. Psychology needs more research relevant to the preparation and roles of health service psychologists and must have an ongoing, comprehensive workforce analysis. 


\title{
Appendix II
}

Health Service Psychology: Preparing Competent Practitioners-Competencies for Science (HSPEC, 2013, p. 423)

\section{A. Scientific Knowledge \& Methods:}

Be knowledgeable about the biological, cognitive, affective, social, and lifespan developmental bases of behavior; be able to critically evaluate relevant literature, and apply that knowledge in practice.

Be knowledgeable about psychological research methods, techniques of data collection and analysis, and apply that knowledge in practice.

Be knowledgeable about psychological clinical research findings fundamental to the provision of health care services, and apply that knowledge in practice.

Be knowledgeable about current information technology and apply that knowledge in practice.

Be familiar with research on how biological, psychological, social, cultural, and economic factors affect health and behavior, disease, treatment outcomes, and wellness, and how to apply that knowledge in practice.

Commentary. HSPs must have a firm grounding in psychological science and statistics, but this is not sufficient. They also need to have a basic familiarity with knowledge from other disciplines such as anatomy, physiology, genetics, pharmacology, anthropology, sociology, and economics. This is not to intended to train "mini physicians" or "mini pharmacists," but to prepare psychologists to be able to appropriately assess and treat problems in their areas of expertise as well as ensure whole person care in collaboration with other health professions, including when to refer. This knowledge base is fundamental to the biopsychosocial model of care, although psychologists' strengths will remain in the psychological/behavioral aspects and their interactions with other components.

\section{B. Research/Evaluation:}

Critically evaluate relevant health and behavior research related to populations to be served.

Conduct research that contributes to the scientific and professional knowledge base or evaluates the effectiveness of various professional activities in health care and health promotion.

Use research skills for program development and evaluation as well as for quality improvement related to health care services.

Be familiar with health research methods.

Commentary. Cross-cutting themes of research relevant to HSPs are related to outcomes assessments, treatment efficacy/effectiveness, patient satisfaction, and quality improvement methods. HSPs must be more than consumers of research, but have skills in conducting practice-based research relevant to quality improvement efforts. They must also understand human subjects and consent issues related to health research.

\author{
(C) 2018, American Psychological Association. This paper is not the copy of record and may not exactly \\ replicate the final, authoritative version of the article. Please do not copy or cite without authors' permission. \\ The final article will be available, upon publication, via its DOI: 10.1037/tep0000222
}

